\title{
Influence of Temperature on Distributed Strain Sensing with OTDR in Polymer Optical Fibers
}

\author{
S. A. Dengler ${ }^{1}$, N. Schmidt ${ }^{1}$, M. Luber ${ }^{1}$, J. Fischer ${ }^{1}$, H. Hangen ${ }^{2}$, O. Ziemann ${ }^{1}$, R. Engelbrecht ${ }^{1}$ \\ ${ }^{1}$ Polymer Optical Fiber Application Center (POF-AC), \\ Technische Hochschule Nürnberg Georg Simon Ohm, \\ Wassertorstraße 10, 90489 Nuremberg, Germany, \\ ${ }^{2}$ HUESKER Synthetic $\mathrm{GmbH}$, \\ Fabrikstraße 13-15, 48712 Gescher, Germany. \\ simon.dengler@pofac.th-nuernberg.de
}

\begin{abstract}
Summary:
Strain in ground and earthworks can be measured by polymer optical fibers (POF) applied to geotextiles. We measure the increase of backscatter (IOB) in the fiber under strain using optical time domain reflectometry (OTDR). The effect of temperature on this measurement principle is investigated. The local backscatter changes by $0.003 \mathrm{~dB} / \mathrm{K}$ for common ambient temperature. In addition it is shown, that temperature depended viscoelastic properties of the polymer does affect IOB.
\end{abstract}

Keywords: optical time domain reflectometry, structural health monitoring, strain sensing, geotextiles, polymer optical fiber

\begin{abstract}
Background
Condition monitoring of critical earthworks as for example dams, dikes and disposal sites is a challenging yet not satisfactorily solved measuring task. A possible sensor consists of a POF applied to a geotextile [1]. Geotextiles are fabrics made of polymer fibers, which are used to absorb stress within the soil and therefore, are ideal to transfer a soil movement to a strain of the sensor fiber.
\end{abstract}

When straining the POF, the level of optical backscattering within the fiber increases along strained sections [2, 3]. Spatially distributed measurements of backscattering, and thus, strain are possible using OTDR.

However, numerous side effects influence measurement accuracy significantly [4]. We previously analyzed relaxation processes that may result from adaptation of the POF material to external force [5]. Additionally, the IOB is affected by temperature and humidity [4]. We will therefore investigate the influence of temperature in this contribution. At first, we will analyze the change of optical backscattering level due to temperature at static unstrained conditions. Secondly, the influence of temperature on IOB due to strain is investigated.

\section{Method}

The backscatter response to temperature is tested on a $20 \mathrm{~m}$ fiber sample. The fiber section between $5 \mathrm{~m}$ to $15 \mathrm{~m}$ is placed in a climate chamber. The temperature is increased from $25^{\circ} \mathrm{C}$ to $30^{\circ} \mathrm{C}, 40^{\circ} \mathrm{C}, 50^{\circ} \mathrm{C}, 60^{\circ} \mathrm{C}$ then cooled down to $50^{\circ} \mathrm{C}, 40^{\circ} \mathrm{C}, 30^{\circ} \mathrm{C}, 25^{\circ} \mathrm{C}, 10^{\circ} \mathrm{C}, 0^{\circ} \mathrm{C}$, $10^{\circ} \mathrm{C},-20^{\circ} \mathrm{C}$ and finally increased to $-10,0^{\circ} \mathrm{C}$, $10^{\circ} \mathrm{C}, 25^{\circ} \mathrm{C}$ again. At each step, the temperature is kept constant for 3h. Arrows in Fig. 1 also indicate the temperature cycle. The ambient temperature was kept constant as well with a conventional air condition unit at $22^{\circ} \mathrm{C}$. OTDR traces were taken automatically in intervals of 10 minutes. The IOB is then determined as the difference between backscatter level inside and outside of the climate chamber (at reference temperature $22^{\circ} \mathrm{C}$ )

In the second experiment, five fibers were strained in identical manner, but exposed to different temperatures. The fibers were acclimatized at measurement temperature for at least $1 \mathrm{~h}$. An automated measurement program strained the fiber at constant time steps of $1 \mathrm{~h}$. In order to transfer the strain to the fiber, two rods were glued to it using a two-component epoxy, where motorized linear drives apply the elongation. Strain was applied at the position $10.0 \mathrm{~m}-$ $10.1 \mathrm{~m}$ increasing over time from $0 \%$ to $10 \%$ in steps of $0.1 \%$. The IOB is calculated as the maximum value above the mean of backscattering level.

For all measurements, we used the same standard PMMA-POF with $1 \mathrm{~mm}$ diameter (Mitsubishi GH-4001-P) and a commercially available POF OTDR (Luciol LOR-220) at $520 \mathrm{~nm}$ wavelength. 


\section{Results}

The temperature dependence of backscattering is shown in Fig. 1. A linear dependence has been estimated.

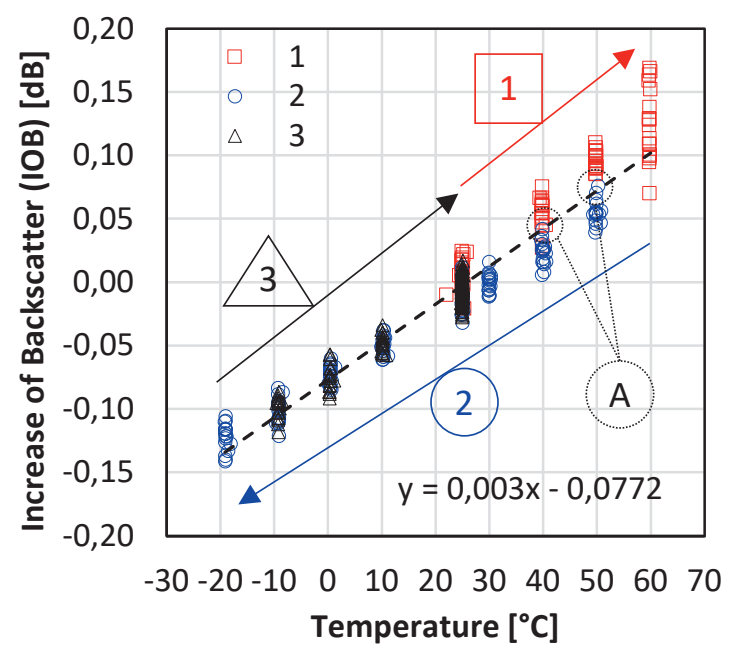

Fig. 2. Temperature dependence of backscattering 1: increasing temperature, 2: decreasing temperature, 3: increasing temperature, A: hysteresis.

In this approximation, the backscattering raises by $0.003 \mathrm{~dB} /{ }^{\circ} \mathrm{K}$ compared to the reference temperature. The measured values have a standard deviation of $\pm 0.015 \mathrm{~dB}$, from the fit. Heating can lead to a hysteresis. In the measurement data of Fig. 1. some deviations at $40^{\circ} \mathrm{C}$ and $50^{\circ} \mathrm{C}$ are noticeable, indicated by "A" in Fig. 1.

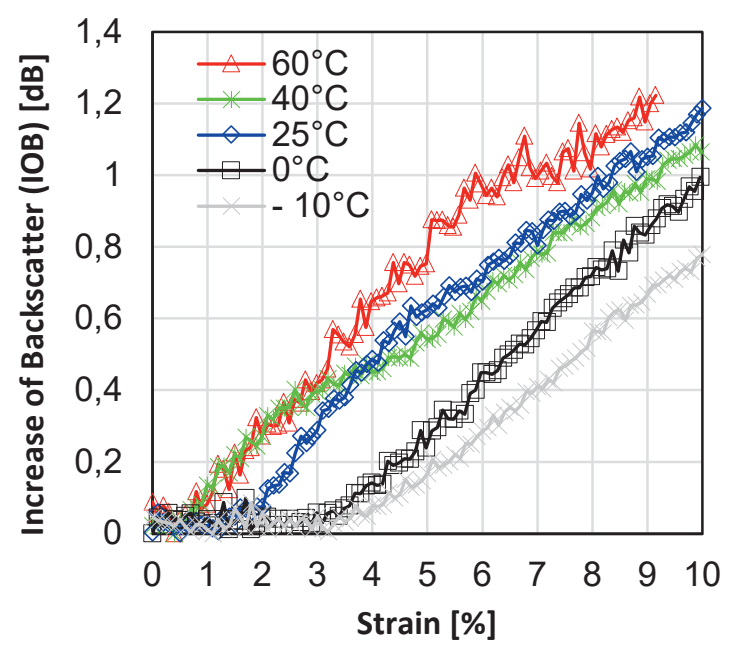

Fig. 2. $\quad I O B$ due to strain at different temperatures

Fig. 2. shows the IOB due to strain at different temperatures. As a noticeably trend, higher slopes and amplitudes correspond to higher temperatures. However, no straight relationship could be derived from the experiment. As the IOB at $<3 \%$ strain does not increase in low temperatures, we additionally measured the force and can confirm that strain was actually applied.

Temperature affects viscoelastic properties and the IOB by strain behavior respectively, as the viscoelastic stress at the fiber changes. The strained interval of $10 \mathrm{~cm}$ is beyond the spatial resolution limit of the OTDR. This affects the results in two ways. First, the absolute value of IOB is higher than in Fig. 2. Second, a small IOB could not be detected accurately. However, the $10 \mathrm{~cm}$ interval was limited due to mechanical restrictions of the climate chamber.

\section{Conclusion}

Temperature could be measured by the change of local backscatter. At this point it is not possible to distinguish strain from temperature. As the effect is small, it adds a measurement uncertainty for strain measurement. There is little uncertainty for small local temperature differences in the application, of soil depth $>1 \mathrm{~m}$, and might therefore be neglectable in most cases.

The altering IOB due to strain properties at different temperatures is an interesting result, which has the potential, to provide deeper understanding on viscoelastic and optical properties of POF. Despite of that, it is a challenge to correct the effect for strain sensing, if necessary.

\section{Acknowledgements}

This work has been funded by the Federal Ministry of Education and Research, funding program Forschung an Fachhochschulen (FHprofUnt) under contract number 13FH137PX6, "Optische Sensoren zur Überwachung von Erdstrukturen (SmartOSE)."

\section{References}

[1] S. Liehr, P. Lenke, K. Krebber, M. Seeger, E. Thiele, H. Metschies, B. Gebreselassie, J. Ch. Münich and L. Stempniewski, Distributed strain measurement with polymer optical fibers integrated into multifunctional geotextiles, Proc. SPIE 7003, 7003-02-7003-15 (2008).

[2] I. R. Husdi, K. Nakamura and S. Ueha, Sensing characteristics of plastic optical fibres measured by optical time domain reflectometry, Meas. Sci.Techn. 15 (8), 1553-1559 (2004)

[3] S. Liehr, Ph. Lenke, M. Wendt, K. Krebber, M. Seeger, E. Thiele, H. Metschies, B. Gebreselassie and J. Ch. Münich; Polymer Optical Fiber Sensors for Distributed Strain Measurement and Application in Structural Health Monitoring, IEEE Sensors J. 9 (11), 1330 - 1338 (2009).

[4] S. Liehr, M. Breithaupt, and K. Krebber; Distributed humidity sensing in PMMA optical fibers at $500 \mathrm{~nm}$ and $650 \mathrm{~nm}$ wavelengths; Sensors 17.4 (2017): 738.

[5] S. Dengler, N. Schmidt, M. Luber, J. Fischer, H. Hangen, O. Ziemann and R. Engelbrecht; Influence of Temporal Strain Evolution on Distributed Strain Sensing with OTDR in Polymer Optical Fibers, SMSI (2020): 75-76. 